\title{
Use of Polyurethane Insulated Panel for Heat Infiltration in Refrigerated Vehicles
}

\section{*11OLUDAISI, ADEKOMAYA; ${ }^{2}$ SULAIMAN, ADEDOYIN; ${ }^{2}$ ADAMA KAYODE}

\author{
${ }^{-}$Department of Mechanical Engineering, Mechatronics and Industrial Design, Tshwane University of Technology, Pretoria, South Africa \\ ${ }^{2}$ Department of Agricultural and Mechanical Engineering, Faculty of Engineering, College of Engineering and Environmental Studies, Olabisi \\ Onabanjo University, Ibogun Campus, Ifo, Ogun State, Nigeria. \\ (Corresponding author: oludaisiyetunde@gmail.com; adekomayao@tut.ac.za adekomaya.oludaisi@oouagoiwoye.edu.ng ) \\ (Corresponding author contact Tel.no +2348034410652, +2348059396975, +27735106113)
}

\begin{abstract}
This study investigates the overall heat transfer coefficient of reinforced composite panel with the aim of being used as the internal and external cover sheet of the insulated panel. The results indicate that the overall heat transfer coefficient, $\mathrm{U}\left(\mathrm{W} / \mathrm{m}^{2} \mathrm{~K}\right)$ value of the composite reinforced with $10 \%$ wt. of fibre at $0^{\circ}$ orientation $\left(\mathrm{G}_{10} \mathrm{E}\right)$ offers the lowest $\mathrm{U}$ value of $0.386950 \mathrm{~W} / \mathrm{m}^{2} \mathrm{~K}$ and $0.196680 \mathrm{~W} / \mathrm{m}^{2} \mathrm{~K}$ for $50 \mathrm{~mm}$ and $100 \mathrm{~mm}$ insulation thicknesses, respectively. This further shows their potential of being used as internal and external cover of insulation materials which may prolong the ageing period of insulation and also the shelf life of fresh raw fruits. (C) JASEM
\end{abstract}

https://dx.doi.org/10.4314/jasem.v21i4.10

Keywords: composite sheets, refrigerated vehicle, energy conservation, fossil fuel, climate change.

Climate change and the emerging environmental conditions have raised the global emission to unprecedented scenario considering its contribution to environmental problems; acid precipitation, ozone depletion, and the greenhouse gas effect (Çomaklı and Yüksel, 2004). The effect of climate change seems to have permeated across continents and these have raised a lot concerns as the earth temperature continues to rise with no specific solution in sight. These effects have resulted in the spreading of desert, rise in sea level and most importantly the biodiversity loss. Fossil fuel energy has been identified (Bakos, 2000) as the most contribution factor to ozone depletion and the demand for this convectional energy is predicted to rise as modern day technology still depend largely on fossil fuel. A significant quantity of fossil fuel is used to maintain and transport fresh raw fruits in refrigerated vehicles and as countries develop their cold chains, this will result in more energy demand (James and James, 2010). Refrigerated vehicle is important as it serves to prolong the safety and quality of harvested raw fruits and enabling food to be conveyed to an increasingly urbanised cities (Tassou et al., 2009). Recently, there have been a quite number of literature reports(Browne et al., 2005, Luè et al., 2014, Balat, 2006) on the role of climate change on "access to food" and "food security" and key of such concerns have dwelled largely on increasingly fossil fuel consumption and its impact on the environment. The depletion of ozone layer have raised the earth's surface temperature to about $0.6^{\circ} \mathrm{C}$ over the last two decades and with the prediction of attaining $2^{\circ} \mathrm{C}$ as affirmed in the last Copenhagen conference on Climate change., and, as a result, the sea level is reported to have risen by almost $20 \mathrm{~cm}$ in the last decades (García-Álvarez et al., 2013).

\begin{tabular}{ll}
\hline List of Symbols & $\mathrm{L}_{1}=\mathrm{L}_{3}$ thickness of the cover sheet \\
\hline $\mathrm{K}$ thermal conductivity value W/m $/ \mathrm{m}^{2} \mathrm{k}$ & $\mathrm{L}_{2}$, thickness of the insulation \\
$\mathrm{S}$ mean surface(the geometric mean of external and internal & \\
surface $\mathrm{m}^{2}$ & \\
$\mathrm{~T}$ temperature & \\
$\mathrm{Q}$ heat flux W & \\
$\mathrm{U}$ overall heat transfer coefficient W/m $/ \mathrm{m}^{2} \mathrm{~K}$ & \\
$\mathrm{~h}_{1}=\mathrm{h}_{2}$ individual heat transfer coefficient W/m $/ \mathrm{m}^{2} \mathrm{~K}$ & \\
\hline
\end{tabular}

$\mathrm{CO}_{2}$ emission from refrigerated vehicles, for instance, is released into the environment causing further changes in the atmosphere with carbon reacting with the oxygen resulting in greenhouse gas and depletion of natural forest and biodiversity loss. Emission from $\mathrm{CO}_{2}$ has increased largely since the industrial revolution from 1950 and has increased at a rate of $0.4 \%$ per year in the last two decades with a projected life time of about 100 years in the atmosphere. These volume of $\mathrm{CO}_{2}$ remain in the atmosphere depleting the nature, enhancing the intensity of acid rain and thereby causing environmental disaster (Burniaux and Chateau, 2014). The majority of refrigerated vehicles are conducted with semi-trailer insulated rigid boxes and presently, there are about 4 million refrigerated vehicles worldwide with the forecast that by 2030 , global road refrigerated vehicles will have multiplied by nearly $2.5 \%$ in a year (Glouannec et al., 2014). In order to minimise energy demand in refrigerated vehicles and its resulting environmental impact, it 
would be of great interest to improve the insulation design (Gvozdenac, 2015). Insulated panels of vehicles transporting perishable raw fruits are normally defined by the value of overall coefficient of heat transfer (k-value) and by extension body porosity. This overall coefficient of heat transfer predicts the rate of transfer of heat or ambient temperature in relation to unit surface of the external walls, when it is subjected under steady conditions and the unit difference of temperature exists between the internal and external atmospheres (Gvozdenac, 2015). Thus, overall heat transfer coefficient is defined by equation 1 as contained in the mathematical expression developed by Dragano et al. (2009).

$$
K=\frac{Q}{S\left(T_{e}-T_{i}\right)}
$$

The solar irradiation through the body wall with polyurethane used as the insulating materials will degrade the optimum performance refrigerated chamber due to high thermal load from the refrigerating unit. In view of the low thermal conductivity value $(\mathrm{k})$ of polyurethane, the interaction between the body wall as a result of temperature rise, causes infrared radiation through conduction into the polyurethane thereby reducing its overall performance efficiency. In this study, attempts were made to replace the external metallic wall of the insulated panel with the composite materials adopting the literature values of already developed composite sheet in order to ascertain the effectiveness of light weight composite polymer material as a potential substitute for metallic reinforced sheet.

\section{MATERIAL AND METHOD}

In this study, light weight composite materials were fabricated from epoxy resin and E-glass fibre and the thrust of the research is to adapt these composite materials as external wall of refrigerated vehicles. Part of the concept of this study is to analyse overall heat transfer coefficient of each of the composite materials developed for thermal insulation. The five (5) specimen composite panel were developed and the manufacturing parameters were based on fibre enhancement and orientation. Successive fibres were oriented with respective to base fibre at $30^{\circ}$ and $60^{\circ}$ orientation basically to study in impact of orientation on overall heat transfer reduction. Some of the key issues that remain unresolved in this manufacturing process is the percentage of fibre contents that is predicted to reach an optimum thermal conductivity value. Measurement of thermal conductivity of these composite specimen were done with a Leinsis TB 100 equipment as illustrated in the graph presented in Figure 1 which was later followed by the estimation of overall heat transfer coefficient of these composite panel. It is also very important to note that insulated body of refrigerated vehicles is being apprised as per heat transfer through external wall by overall coefficient of heat transfer (U-value)

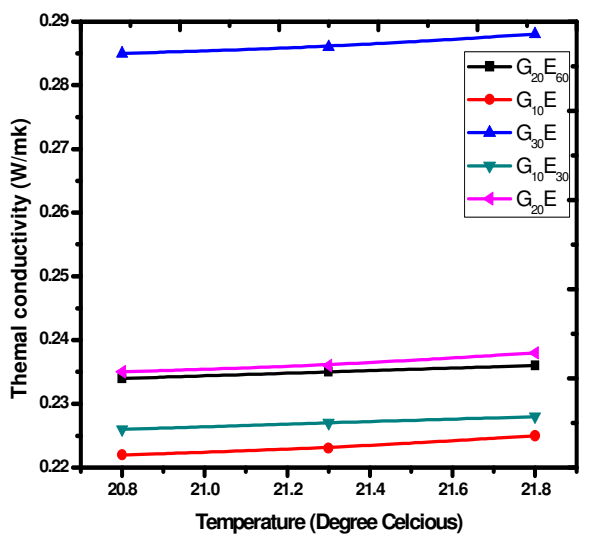

Fig 1: Measured thermal conductivity values of composite specimens under varying degree of ambient temperature

\section{RESULTS AND DISCUSSION}

The computation of the overall heat transfer coefficient is quite important especially for the light weight composite materials in order to analyse their potential to limit heat infiltration when compared with the aluminium sheet and iron metal. The thickness of the insulation is also x-rayed in this study as per their effectiveness in maintaining optimal cold cycle chain. Insulation and low thermal conductivity composite materials have been widely reported to reduce the air infiltration and to maintain cooling in refrigerated chamber, especially in severe climates and in line with this concept, the Table 1 provided the literature data that was adapted in the analysis of the overall heat transfer coefficient as exemplified in equation 2 which has also been used in many literatures (Adekomaya et al., 2017, Mohsen and Akash, 2001, Mahlia et al., 2007) to estimate overall heat transfer coefficient.

$$
U=\frac{1}{\frac{1}{h_{i}}+\sum_{i=1}^{3} \frac{L_{i}}{k_{i}}+\frac{1}{h_{2}}}
$$

Table 1: Parameters used in calculation

\begin{tabular}{ll}
\hline Parameter & Value \\
\hline$h_{1}=h_{2}$ & $30 \mathrm{~W} / \mathrm{m}^{2} \mathrm{~K}$ \\
Insulation & Polyurethane \\
$\mathrm{K}_{2}$ & $0.02 \mathrm{~W} / \mathrm{mK}$ \\
$\mathrm{L}_{1}=\mathrm{L}_{3}$ & $0.002 \mathrm{~m}$ \\
$\mathrm{~L}_{2}$ & $50,75,100(\mathrm{~mm})$ \\
Length of the panel & $1000 \mathrm{~mm}$ \\
Width of the panel & $1000 \mathrm{~mm}$ \\
AISI density for Aluminium & $2.7 \mathrm{~g} / \mathrm{cm}^{3}$ \\
AISI density for iron sheet & $7.87 \mathrm{~g} / \mathrm{cm}^{3}$ \\
Density of polyurethane insulation & $30 \mathrm{Kg} / \mathrm{m}^{3}$ \\
\hline
\end{tabular}




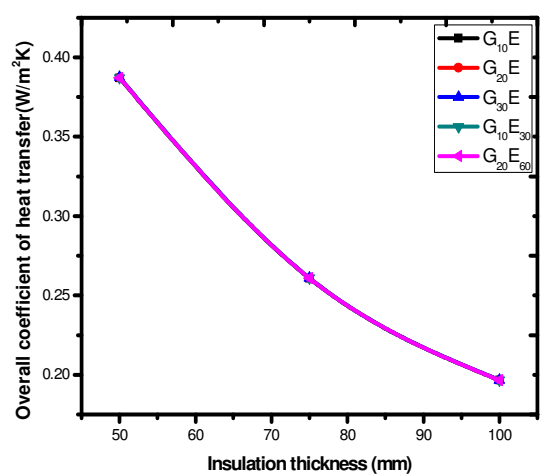

Fig 2: Insulation thickness against overall heat transfer coefficient of the five composite specimens

Figure 2 shows the plots of coefficient of heat transfer of all the composite sheets at various degree of insulation thickness in the range of $50 \mathrm{~mm}$ to $100 \mathrm{~mm}$ and it can be seen from this plot that significant difference is not noticed among the panels regardless of fibre loading and orientation. The implication of these may inform more insulation thickness to reduce heat infiltration through the external wall. It can also be noticed that $\mathrm{G}_{10} \mathrm{E}$ appears to have the lowest heat transfer coefficient, as depicted in the plot, further interpretation to this result indicates that the successive fibre loading at any degree of orientation may not necessarily reduce heat transfer through the external wall.

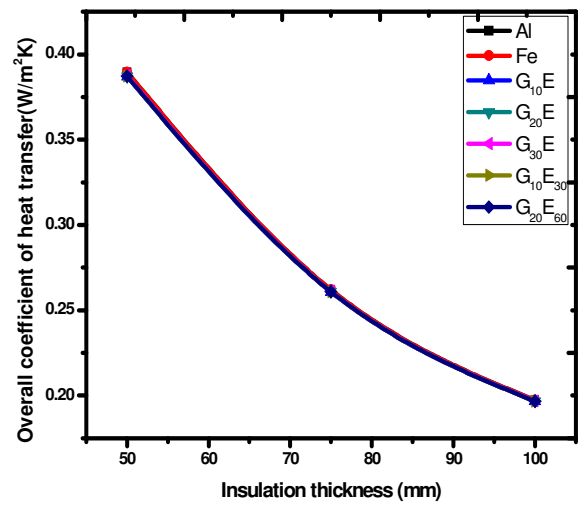

Fig 3: Insulation thickness against overall heat transfer coefficient of metallic materials and the five composite specimens

The plot shown in Figure 3 has further given credence to past works as it is crystal clear that using aluminium material as cover sheet for heavily insulated panel may not necessarily lower the overall heat transfer coefficient as the percentage of heat infiltration between these regions is insignificant. The new composite materials developed, exhibited a promising view in line with the low thermal conductivity estimate. It is also very important to illustrate that the heat transfer coefficient of new materials, slightly improve when compared to iron and metallic sheets. Significant difference in the heat transfer coefficient is not noticed in these new materials when compared with metallic sheet, but the overall heat rejection using these new materials as external wall will culminate into energy saving in refrigerated vehicles. Further analysis of this result showed that with $50 \mathrm{~mm}$ as insulating thickness and using $\mathrm{G}_{10} \mathrm{E}$ as external cover sheet, there is likely to be $0.6 \%$ heat reduction over aluminium sheet, which to a larger extent, must have saved significant energy requirement in refrigerated vehicles.

Conclusion: his experimental study has shown clearly the magnitude of overall heat transfer coefficients of composite panels developed on the basis of fibre loading and orientation. It is also important to note that while the difference in metallic reinforced panel and the composite panel developed seem to have shown little difference as demonstrated in the plots, further study may be required to achieve lower overall heat transfer coefficients. Although, the application of nano-particles in composite formation appears to have improved the mechanical properties as reported in many literatures, this study futures the introduction of nano-materials as reinforcement in these composite for more lower overall heat transfer coefficient values.

Acknowledgement: The author would like to thank Tshwane University of Technology, Pretoria, South Africa for the platform to conduct this research. The authors would also appreciate some of the literatures that have provided comprehensive background of glass fibre.

\section{REFERENCES}

ADEKOMAYA, O; JAMIRU, T; SADIKU, R; HUAN, Z (2017). Minimizing energy consumption in refrigerated vehicles through alternative external wall. Renewable and Sustainable Energy Reviews, 67, 89-93.

BAKOS, G. C (2000). Insulation protection studies for energy saving in residential and tertiary sector. Energy and Buildings, 31, 251-259.

BALAT, M (2006). Energy and greenhouse gas emissions: A global perspective. Energy Sources, Part B, 1, 157-170.

BROWNE, M; ALLEN, J; ANDERSON, S (2005). Low emission zones: the likely effects on the freight transport sector. International Journal of Logistics: Research and Applications, 8, 269281.

BURNIAUX, M; CHATEAU, J (2014) Greenhouse gases mitigation potential and economic 
efficiency of phasing-out fossil fuel subsidies. International Economics, 140, 71-88.

ÇOMAKLı, K; YÜKSEL, B (2004). Environmental impact of thermal insulation thickness in buildings. Applied Thermal Engineering, 24, 933-940.

DRAGANO, A; ROSSI, S; BISON, P; PANOZZO, G (2009). Experimental evaluation of the optical absorption coefficient of a sandwich panel for insulated vehicles. Quantitative InfraRed Thermography Journal, 6, 207-223.

GARCÍA-ÁLVAREZ，A; PÉREZ-MARTÍNEZ，P; GONZÁLEZ-FRANCO, I (2013). Energy consumption and carbon dioxide emissions in rail and road freight transport in Spain: a case study of car carriers and bulk petrochemicals. Journal Of Intelligent Transportation Systems, 17, 233-244.

GLOUANNEC, P; MICHEL, B; DELAMARRE, G; GROHENS, Y (2014). Experimental and numerical study of heat transfer across insulation wall of a refrigerated integral panel van. Applied Thermal Engineering, 73, 196-204.

GVOZDENAC, D (2015). An unsteady-state method for determining overall coefficient of heat transfer ( $\mathrm{k}$-value) of insulated bodies at variable external temperatures. Heat and Mass Transfer, 51, 171-180.
JAMES, S. J; JAMES, C (2010). The food coldchain and climate change. Food Research International, 43, 1944-1956.

LUÈ, A; BRESCIANI, C; COLORNI, A; LIA, F; MARAS, V; RADMILOVIĆ, Z; WHITMARSH, L; XENIAS, D; ANOYRKATI, E (2014). Future priorities for a climate-friendly transport. A European Strategic Research Agenda towards 2030. International Journal of Sustainable Transportation.

MAHLIA, T; TAUFIQ, B. N; ISMAIL H (2007). Correlation between thermal conductivity and the thickness of selected insulation materials for building wall. Energy and Buildings, 39, 182187.

MOHSEN, M. S; AKASH, B. A (2001). Some prospects of energy savings in buildings. Energy Conversion and Management, 42, 1307-1315.

TASSOU, S. A; DE-LILLE, G; GE, Y. T (2009). Food transport refrigeration - Approaches to reduce energy consumption and environmental impacts of road transport. Applied Thermal Engineering, 29, 1467-1477. 